\title{
Preliminary Study of Electrochemical Advanced Oxidation of Organic Dyes on TiO2
}

\author{
Alexandra Banu $^{1}$, Madalina Mocirla ${ }^{1, *}$ and GizemNur Soylu ${ }^{2}$ \\ ${ }^{1}$ Politehnica University of Bucharest, Department of Manufacturing Technology, Splaiul \\ Independenței, no. 313, sector 6, Bucharest, RO-060042, Romania \\ ${ }^{2}$ University of Kocaeli, Kocaeli, Umuttepe Yerleskesi,41380, Turkey
}

\begin{abstract}
Methyl orange (MO) is an environmental concern because their degradation products are highly toxic to aquatic microorganisms and carcinogenic, also their degradation products are mutagenic to humans. Electrochemical oxidation is one of the promising technologies for the dye wastewater de-pollution, which are obtained extensively attentions because it holds the advantages of total oxidization of dyes to $\mathrm{CO} 2$ and $\mathrm{H} 2 \mathrm{O}$. Titanium dioxide has emerged as the leading candidate to provide complete destruction of organic pollutants via heterogeneous photocatalysis that result in total mineralization of many organic pollutants. Though this process offers actual annihilation of the dye moleculesatavery high efficiency, thepost-treatmentrecoveryof $\mathrm{TiO} 2$ canbecostly. The titanium nanotubes are typically produced by anodic oxidation of the titanium foil in various electrolytes.Degradation of methyl orange (MO) was conducted by electrochemical oxidation method with $\mathrm{Ti} / \mathrm{TiO} 2$ nanotubes anodes. Were prepared samples of $\mathrm{TiO} 2$ nanotubes by anodizing titanium in an electrochemical bath consisting of 1:1 waterglycerol with $0.4 \%$ of $\mathrm{HF}$ using different conditions: $25 \mathrm{~V}$ for 8 hours, $30 \mathrm{~V}$ for 3 hours in the stationary state, $30 \mathrm{~V} 3$ hours under ultrasound stirring. The oxidation efficiency was determined by UV-VIS analysis of the electrolyte.
\end{abstract}

\section{Introduction}

Azo dyes such methyl orange, which contain one or more azo bonds $(\mathrm{N}=\mathrm{N}-)$ as a chromophore group in association with aromatic structures are toxic to aquatic ecosystems and are not efficiently degraded by conventional aerobic wastewater treatments. One of the effective technologies for degradation of dye waste water is the electrochemical oxidation (EO). This process can have many advantages, like the potential of complete oxidization of dyes to $\mathrm{CO}_{2}$ and $\mathrm{H}_{2} \mathrm{O}$, operation at room temperature and atmospheric pressure, simple process and so all. Electrode materials have an important effect on the life of electrode and the production of active species. It has been scientifically demonstrated the fact that $\mathrm{TiO}_{2}$ is the only candidate which can completely destroy the organic pollutants through a heterogeneous photo catalysis. The result of this process is mineralization of organic

*Corresponding author: mady9266@yahoo.com 
pollutants. A material can be an efficient photo catalyst if its structure is so organized as to minimize the possibility of recombining the photo generated hole- electron pair. Because the hole recombination length in $\mathrm{TiO} 2$ is about $100 \mathrm{~nm}$, the optimal architecture must be a nano-structured material [1]. Consequently, many works have focused on the preparation of $\mathrm{TiO}_{2}$ nano-rods [2,3], nanowires [4,5] and nanotubes [6]. Most researchers agree, that the $\mathrm{TiO}_{2}$ nanotubes offer a high potential in photocatalytic activity [7-8]. At the same time, it is well known that the photocatalytic activity of $\mathrm{TiO}_{2}$ depends on its crystalline structure, $\mathrm{Yu}$ [9] demonstrated that $\mathrm{TiO}_{2}$ nanotubes formed $100 \%$ of the anatase have the highest photocatalytic efficiency. The photocatalytic properties of $\mathrm{TiO}_{2}$ nanotubes for dye degradation are being evaluated for certain reasons. There are few interfacial grain boundaries in $\mathrm{TiO}_{2}$ nanotubes if we were to compare with $\mathrm{TiO}_{2}$ nanoparticles. Due to this, there was an improvement of the redox catalytic properties at the $\mathrm{TiO}_{2}$ surface. Because there is less grain boundaries which assist in promoting charge (electron-hole) transport. It is well known the fact that improved charge transport favors photo- catalytic degradation of pollutants. Photo- catalytic dye degradation can clearly be improved through this treatment. The main objective of this paper is to highlight the influence of the electrochemically growth parameters of Titania Nano Tubs (TNT) on the efficiency of advanced oxidation of Methyl Orange.

\section{Experimental details}

As a support material for electrodes it was used the Ti6Al4V alloy in forged state whose chemical composition is presented in table 1 .

Before the electrochemical growth of the $\mathrm{TiO} 2$ the surfaces of the samples were polished with abrasive paper and aluminum oxide powder to the metallographic quality, followed by demineralized water wash in the ultrasound bath and finally with ethanol. After that, the specimens were pickled for 2 minutes of in $40 \%$ HF solution and transferred, without further washing, into the electrochemical cell. The electrolyte used for $\mathrm{TiO}_{2}$ growth was a solution of $0.4 \% \mathrm{HF}$ solution in water: glycerin $=1: 1$ mixture.

For Methyl Orange oxidation it was used a solution of $50 \mathrm{mg} \mathrm{L}^{-1}$ in $0,1 \mathrm{M} \mathrm{Na}_{2} \mathrm{SO}_{4}$. All usedmaterials were of analytical grade.

Table 1. The chemical composition of titanium alloy (w \%)

\begin{tabular}{|c|c|c|c|}
\hline $\mathrm{Al}$ & $\mathrm{V}$ & $\mathrm{Fe}$ & $\mathrm{Ti}$ \\
\hline 5,8 & 3,7 & 0,98 & base \\
\hline
\end{tabular}

There have been used 3 methods for the anodic growth of $\mathrm{TiO}_{2}$, by applying an external tension from a power DC source Velleman PS613.

1. Under of an external bias-of $25 \mathrm{~V}$ for 8 hours in stationary conditions.

2. Under of an external bias -of $25 \mathrm{~V}$ for 3 hours under the ultrasonic field of $80 \mathrm{Khz}$.

3. Under of an external bias -of $30 \mathrm{~V}$ for 3 in stationary conditions.

After oxidation, the specimens were ultra-sonicated using the demineralized water for 4 min to remove the excess of titanium dioxide and then dried by wiping with filter paper. The oxidized samples were subjected to thermal treatment at $400^{\circ} \mathrm{C}$ for one hour, in order to convert $\mathrm{TiO} 2$ into Anatase form. The morphological analysis of the samples was made by scanning electronic microscopy, SEM, with a FEI INSPECT microscope. 
Electrochemical oxidation of MO has been preceded in a standardthree electrodes electrochemical cell, using a platinum foil as an auxiliary electrode and $\mathrm{Ag} / \mathrm{AgCl} 3,5 \mathrm{~N}$ as a reference electrode. The surface of the auxiliary electrode was about 1.5 times larger as the surface the working specimen.

The MO oxidation was conducted electrochemically using a Voltalab 10 Galvanostat/Potentiostate instrument with the Voltamaster software for data processing.

In order to establish the oxidation parameters for Methyl Orange destroying were acquired the cyclic voltammograms performed with the potential scan of $50 \mathrm{mVmin}^{-1}$ and $100 \mathrm{mV} \mathrm{min} \mathrm{m}^{-1}$ between $-600 \mathrm{mV}$ and $+1200 \mathrm{mV}$ vs $\mathrm{Ag} / \mathrm{AgCl}$ electrode.

The MO electro-oxidation was conducted chronoamperometrically at $+600 \mathrm{mV} / \mathrm{Ag} / \mathrm{AgCl}$ during $60 \mathrm{~min}$.

The efficiency of the electrochemical oxidation of MO was appreciated through the UV VIS analysis of the electrolyte at the end of the tests by UV VIS CINTRA 202 equipment.

\section{Results and discussions}

\subsection{The results of the morphological analysis of the $\mathrm{Ti}_{6} \mathrm{Al}_{4} \mathrm{~V}$ samples after the growth of titanium nanotubes by electrochemical oxidation are being shown in Fig. 1 a, b, c.}

Specimens were labeled as is displayed in table 2.

Table 2. Notation of the test samples used in the electrochemically tests

\begin{tabular}{|l|l|l|l|}
\hline \multicolumn{1}{|c|}{ Specimens label } & \multicolumn{1}{|c|}{ P1 } & \multicolumn{1}{c|}{ P2 P3 } \\
\hline $\begin{array}{l}\text { Conditions of } \\
\text { oxidation }\end{array}$ & $\begin{array}{l}\text { 25V- 8hours - } \\
\text { stationary state }\end{array}$ & $\begin{array}{l}\text { 30 V- 3 hours - } \\
\text { under sonication }\end{array}$ & $\begin{array}{l}\text { 30V-3 hours- } \\
\text { stationary state }\end{array}$ \\
\hline
\end{tabular}

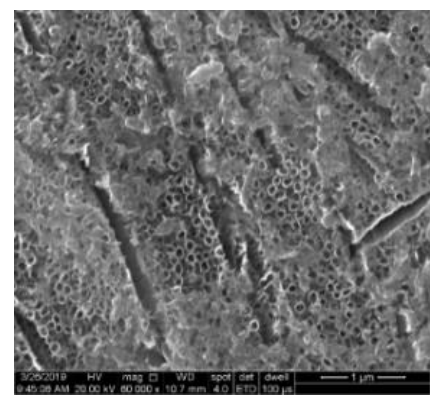

a

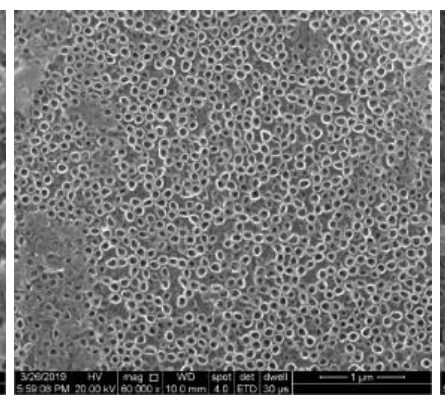

b

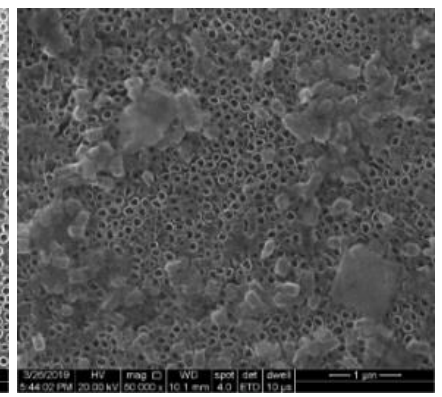

c

Fig. 1. The morphological aspect (SEM) of electrochemically coated surfaces with TNT under different conditions (before ultrasonicated for removal of superficial oxide sheets): a) $25 \mathrm{~V}-8$ hours stationary state (P1), b) 30V-3 hours in an ultrasonic field (P2), c) 30V-3 hours stationary state (P3).

From figure 1 it results the fact that the nanotubes obtained in the ultrasonic field present a more uniform distribution on the surface compared with those obtained under the same voltage in stationary condition. The hydrodynamic regime created by the ultrasonic field removes excess oxide from the surface in a larger proportion. (Fig.1b versus fig.1c). The increase in oxidation time from 3 to 8 hours even if the potential was lower, $25 \mathrm{~V}$, resulted in the fragmentation of the nanotubes layer as seen in Fig 1a by the appearance of cracks or discontinuities. Also in the case of sample P3 it was not completely removed the layer of $\mathrm{TiO}_{2}$ shallow after ultra-sonication for $4 \mathrm{~min}$. In terms of the average size of nanotubes there are significant differences according to the conditions of obtaining them, thus in the presence of the ultrasonic field in the $\mathrm{TiO}_{2}$ nanotubes have a more regular form 
and the average diameter is around $300 \mathrm{~nm}$, while in stationary conditions the average diameter is around $250 \mathrm{~nm}$. It is to be stressed the fact that at longer oxidation times at the potential of $25 \mathrm{~V}$ besides arranging NTN in separate bands, the average diameter of them is less than $100 \mathrm{~nm}$.

\subsection{Electrochemical oxidation of MO}

The results of electrochemical characterization of TiAlV alloy covered with TNT are being shown in Fig. 2-4. The geometrical surface of each sample was at $1 \mathrm{~cm}^{2}$, and can't be estimated at the moment, the real surface area. For this reason, have to be pointed out that the current density as was displayed on graphs is one apparently, not real, and we named it "app" current density.

Two electrochemical methods were used for the oxidation of MO. First, the cyclic voltammograms was acquired in the absence and in the presence of MO from which the value of the oxidation potential at $600 \mathrm{mV} / \mathrm{Ag} / \mathrm{ClAg}$ was established. As oxidation method Chronoamperometry was used; it consisted of recording the current density value over time under a previously selected of $600 \mathrm{mV} / \mathrm{Ag} / \mathrm{ClAg}$ oxidation potential.

For the determination of the catalytic effect to the electrochemical oxidation of the MO of these systems, there was used a solution of $50 \mathrm{ml} \mathrm{L} \mathrm{MO}$ in $0.1 \mathrm{M} \mathrm{Na}_{2} \mathrm{SO}_{4}$ in order to increase the conductivity of the solution. To highlight the electrochemical in take of the MO oxidation reaction, the curves were acquired both in the supporting electrolyte and in the MO containing solution (Figure 2).

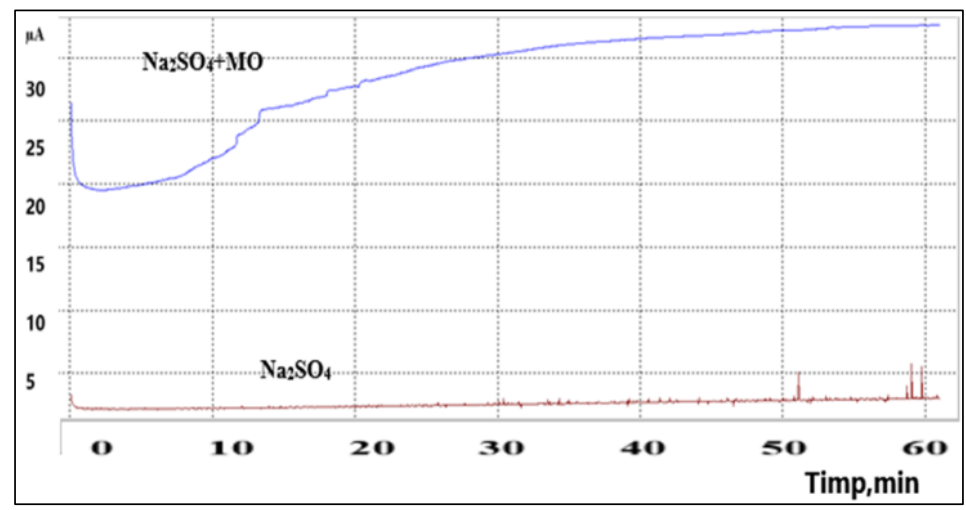

Fig. 2. Chronoamperometric curves of $\mathrm{P} 2$ at $600 \mathrm{mV} / \mathrm{AgClAg}$; $1-\mathrm{Na}_{2} \mathrm{SO}_{4}, 2-\mathrm{Na}_{2} \mathrm{SO}_{4}+\mathrm{MO}$

It can be observed in the fig. 2 that in the absence of MO the "app" current density was of $2 \mathrm{mAcm}^{-2}$, while in the presence of MO the current density is over $30 \mathrm{~mA} \mathrm{~cm}^{-2}$, therefore MO oxidizes electrochemical on the surface covered with TNT.

Figure 3 shows the Chronoamperometric curves for MO electro-oxidation of the three specimens.

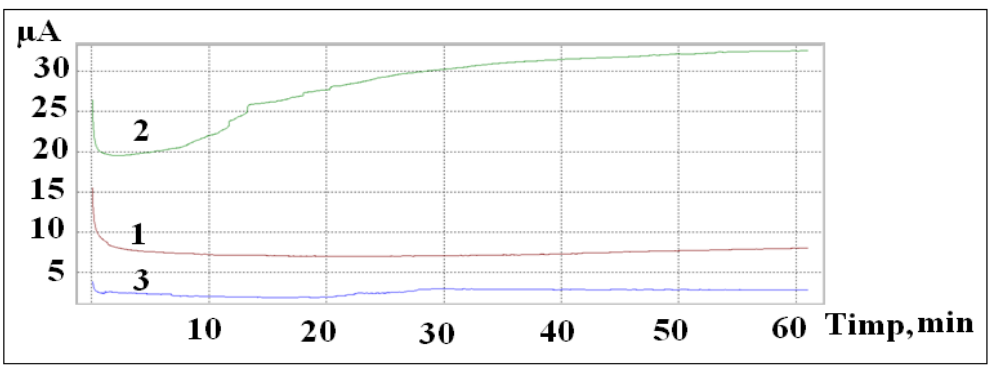

Fig. 3. Chronoamperometric curves acquired in solution of $\mathrm{Na}_{2} \mathrm{SO}_{4} \mathrm{MO}$ for 60 minutes at the potential of $600 \mathrm{mV}$ 
As can be seen in fig. 3, the oxidation of MO occurs at a higher rate on the nanotubes obtained by anodic oxidation in the ultrasonic field (P2). Due to the agitation of the electrolyte under the action of ultrasound, the diffusion at the double electric layer is eliminated and probably the growth rate of the nanotubes is controlled by the solid phase processes. The micrograph of Figure $1 \mathrm{~b}$ shows the formation of nanotubes in overlapping layers, which contributes to increasing the number of active catalytic centers on the surface.

TNT formed in stationary conditions, where the diffusion through the electrical double layer is controlling step of the process, at a lower voltage $(\mathrm{P} 1-25 \mathrm{~V})$ has been increasing the nucleation rate, so the average diameter of the tubes it is a little bit smaller. As a consequence, the real surface area is larger for P1 and this explains the differences between "app" current densities 1 and 3 (fig 3).

At the end of the electrochemical oxidation at $600 \mathrm{mV}$ of the MO on the electrodes, the UV VIS analysis of the electrolytes has been performed in order to observe the MO concentration diminishing. The catalytic efficiency of $\mathrm{TiO} 2$ nanotubes concerning the oxidation of the MO was also highlighted by UV-VIS analysis of the electrolytes before and after oxidation for $60 \mathrm{~min}$. The absorbance curves of the 4 electrolytes are being shown in Fig 4, from which it can be observed that the most important decrease in the MO concentration compared with the initial one was obtained after the oxidation on sample P2.

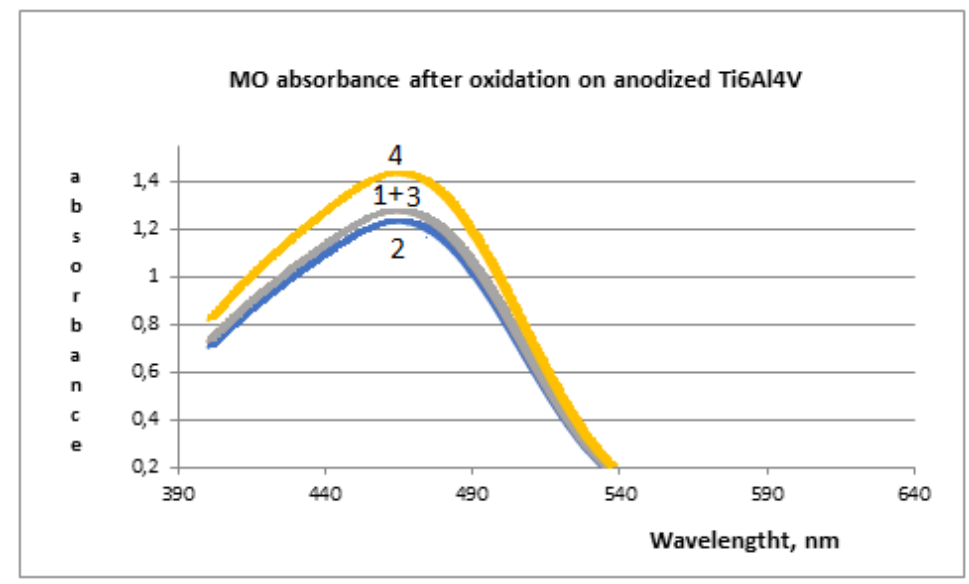

Fig. 4. The curves of MO absorbance after 60 minutes of electrochemical oxidation on anodized $\mathrm{Ti}_{6} \mathrm{Al}_{4} \mathrm{~V}$ in different conditions: curve 1-on sample $\mathrm{P} 1$; curve 2- on sample $\mathrm{P} 2$; curve 3-on sample $\mathrm{P}$; curve 4 initial solution

The UV VIS analysis did not identify differences in MO concentration after oxidation on samples P1 and P3, even if the amperometric curves highlighted a slight modification (the curves 1 and 3 are perfectly over layered).

\section{Conclusions}

- The morphology and catalytic activity of the $\mathrm{TiO}_{2}$ nanotubes is influenced, not only by the electrical tension and time but also by the hydrodynamic conditions of formation.

- The nanotubes obtained in the ultrasonic field present a more uniform distribution on the surface compared with those obtained under the same voltage in stationary condition. 
- The increase of oxidation time from 3 to 8 hours resulted in the fragmentation of the nanotubes layer and at the appearance of cracks.

- It appears that at lower tension and at the increasing of formation time the average diameter of nanotubes diminishes.

- $\quad \mathrm{TiO}_{2}$ nanotubes have a catalytic effect on methyl orange electrooxidation.

- $\mathrm{TiO} 2$ nanotubes obtained by ultrasonication have higher catalytic activity compared to those obtained under stationary conditions, forelectrooxidation reaction of $\mathrm{MO}$; this is highlighted by the increase of oxidation current density and by the decreasing of UV absorbance.

\section{References}

1. W.H. Lubberhuizen, D. Vanmaekelbergh, E. Van Faassen, J. Porous Mater. 7, 147, (2000)

2. K. Melghit, K. Bouziane, J. Alloys Compd. 453, 102, (2008)

3. X.H. Xia, Y.S. Luo, Z.Wang, Y. Liang, J. Fan, Z.J. Jia, Z.H. Chen, Mater. Lett. 61, 2571, (2007)

4. Y. Lin, Mater. Lett. $62,1246,(2008)$

5. B. Wang, Y. Shi, D. Xue, J. Solid State Chem. 180, 1028, (2007)

6. D. Fang, K. Huang, S. Liu, Z. Li, J. Alloys Compd. 464 , L5, (2008)

7. Y. Xie, Electrochim. Acta 51, 3399, (2006)

8. S.G. Yang, Y.Z. Liu, C. Sun, Appl. Catal. A. 301, 284, (2006)

9. J. Yu, H. Yu, B. Cheng, C. Trapalis, J. Mol. Catal. A. 249, 135, (2006) 